Falcone Guido (Orcid ID: 0000-0002-6407-0302)

Leasure Audrey (Orcid ID: 0000-0002-9462-5022)

Meschia James (Orcid ID: 0000-0002-4475-8142)

Biffi Alessandro (Orcid ID: 0000-0001-7063-455X)

\title{
Genetically Elevated LDL Associates with Lower Risk of Intracerebral Hemorrhage
}

\author{
Guido J. Falcone MD ScD MPH ${ }^{\star 1}$, Elayna Kirsch BA ${ }^{\star 1}$, Julian N. Acosta ${ }^{1}$ MD, \\ Rommell B. Noche $\mathrm{MS}^{1}$, Audrey Leasure BS ${ }^{1}$, Sandro Marini MD², \\ Jaeyoon Chung $\mathrm{PhD}^{2}$, Magdy Selim MD PhD³, James F. Meschia $\mathrm{MD}^{4}$,
}

Devin L. Brown MD MS ${ }^{5}$, Bradford B. Worrall MD MSc ${ }^{6}$, David L. Tirschwell MD MSc ${ }^{7}$, Jeremiasz M. Jagiella MD PhD ${ }^{8}$, Helena Schmidt MD ${ }^{9}$, Jordi Jimenez-Conde MD PhD ${ }^{10,11}$, Israel Fernandez-Cadenas $\mathrm{PhD}^{12}$, Arne Lindgren $\mathrm{MD}^{13,14}$, Agnieszka Slowik MD PhD ${ }^{8}$, Dipender Gill MD ${ }^{15}$, Michael Holmes MBBS PhD ${ }^{16,17}$, Chia-Ling Phuah MD MMSc ${ }^{18}$, Nils H. Petersen MD MSc ${ }^{1}$, Charles N. Matouk ${ }^{19}$, Murat Gunel MD ${ }^{19}$, Lauren Sansing MD MSc ${ }^{20}$, Derrick Bennett PhD CStat ${ }^{17}$, Zhengming Chen DPhil ${ }^{17}$, Luan Luan Sun DPhil21, Robert Clarke MD ${ }^{17}$, Robin G. Walters PhD ${ }^{16,17}$, Thomas M. Gill MD ${ }^{22}$, Alessandro Biffi MD²,23-25, Sekar Kathiresan MD $2,23,27$, Carl D. Langefeld $\mathrm{PhD}^{29}$, Daniel Woo MD MSc ${ }^{30}$, Jonathan Rosand MD MSc ${ }^{2,23,26,31}$, Kevin N. Sheth MD*1, Christopher D. Anderson MD MMSc ${ }^{\star 2,23,26,31}$, For the International Stroke Genetics Consortium

\section{* Contributed equally}

\section{Affiliations:}

1. Division of Neurocritical Care \& Emergency Neurology, Department of Neurology, Yale School of Medicine, New Haven, CT

2. Center for Genomic Medicine, Massachusetts General Hospital (MGH), Boston, MA, USA

This is the author manuscript accepted for publication and has undergone full peer review but has not been through the copyediting, typesetting, pagination and proofreading process, which may lead to differences between this version and the Version of Record. Please cite this article as doi: 10.1002/ana.25740

This article is protected by copyright. All rights reserved. 
3. Department of Neurology, Harvard Medical School, Beth Israel Deaconess Medical Center, Boston, MA

4. Department of Neurology, Mayo Clinic, Jacksonville, FL

5. Stroke Program, Department of Neurology, University of Michigan Health System, Ann Arbor, MI

6. Department of Neurology and Public Health Sciences, University of Virginia Health System, Charlottesville, VA

7. Stroke Center, Harborview Medical Center, University of Washington, Seattle, WA

8. Department of Neurology, Jagiellonian University Medical College, Kraków, Poland

9. Institute of Molecular Biology and Medical Biochemistry, Medical University Graz, Austria

10. Neurovascular Research Unit, Department of Neurology, Institut Municipal d'Investigacio' Medica-Hospital del Mar, Universitat Autonoma de Barcelona, Barcelona, Spain

11. Program in Inflammation and Cardiovascular Disorders, Institut Municipal d'Investigacio' Medica-Hospital del Mar, Universitat Autonoma de Barcelona, Barcelona, Spain

12. Neurovascular Research Laboratory and Neurovascular Unit, Institut de Recerca, Hospital Vall d'Hebron, Universitat Autonoma de Barcelona, Barcelona, Spain

13. Department of Clinical Sciences Lund, Neurology, Lund University, Lund, Sweden

14. Department of Neurology, Skåne University Hospital, Lund, Sweden

15. Department of Epidemiology and Biostatistics and Department of Stroke Medicine, Imperial College London, London, United Kingdom

16. Medical Research Council Population Health Research Unit, University of Oxford, Oxford, UK

17. Clinical Trial Service Unit and Epidemiological Studies Unit, Nuffield Department of Population Health, Medical Research Council Population Health Research Unit, University of Oxford, Oxford, UK

18. Department of Neurology, Washington University School of Medicine in St. Louis, St. Louis, MO

19. Department of Neurosurgery, Yale School of Medicine, New Haven, CT

20. Division of Vascular Neurology and Stroke, Department of Neurology, Yale School of Medicine, New Haven, CT

21. Cardiovascular Epidemiology Unit, Department of Public Health and Primary Care, University of Cambridge, Cambridge, UK

22. Department of Internal Medicine, Geriatric Medicine, Yale School of Medicine, New Haven, CT

23. Program in Medical and Population Genetics, Broad Institute, Cambridge MA, USA

24. Division of Behavioral Neurology, Department of Neurology, MGH, Boston, MA

25. Division of Psychiatry, Department of Psychiatry, MGH, Boston, MA

26. Department of Neurology, MGH, Boston, MA

27. Cardiovascular Disease Prevention Center, MGH, Boston, MA

28. Department of Biostatistics and Epidemiology, Perelman School of Medicine, Philadelphia, PA

29. Department of Biostatistical Sciences, Wake Forest School of Medicine, Winston-Salem, NC

30. Department of Neurology, University of Cincinnati College of Medicine, Cincinnati, $\mathrm{OH}$

31. Henry and Allison McCance Center for Brain Health, MGH, Boston, MA, USA 


\section{Correspondence:}

Guido J. Falcone, MD ScD MPH

15 York Street, LLCI Room 1004D

P.O. Box 208018

New Haven, CT 06510, USA

Email: guido.falcone@yale.edu
Christopher D. Anderson MD MMSc

185 Cambridge Street

CPZN 6818

Boston, MA 02114, USA

Email: cdanderson@mgh.harvard.edu 
Genetically Elevated LDL Associates with Lower Risk of Intracerebral Hemorrhage

Running head:

Key Words:

Title word count

Title character count:

Running head word count:

Running head character count:

Abstract Word Count:

Manuscript Word Count:

Tables:

Supplementary Tables:

References:
Genetic studies of blood lipids and ICH risk

Stroke

Hemorrhagic stroke

Intracerebral hemorrhage

Cholesterol levels

Hypercholesterolemia

Stroke genetics

Mendelian randomization

Polygenic risk score 


\begin{abstract}
Objective: Observational studies point to an inverse correlation between LDL cholesterol levels and risk of intracerebral hemorrhage $(\mathrm{ICH})$, but it remains unclear whether this association is causal. We tested the hypothesis that genetically-elevated LDL is associated with reduced risk of $\mathrm{ICH}$.
\end{abstract}

Methods: We constructed one polygenic risk score (PRS) per lipid trait (total cholesterol, LDL, HDL and triglycerides) using independent genome-wide significant SNPs for each trait. We used data from 316,428 individuals enrolled in the UK Biobank to estimate the effect of each PRS on its corresponding trait, and data from $1,286 \mathrm{ICH}$ cases and 1,261 matched controls to estimate the effect of each PRS on $\mathrm{ICH}$ risk. We used these estimates to conduct Mendelian Randomization analyses.

Results: We identified 410, 339, 393, and 317 lipid-related SNPs for total cholesterol, LDL, HDL and triglycerides, respectively. All four PRSs were strongly associated with their corresponding trait (all $\left.p<1 \times 10^{-100}\right)$. While one standard deviation increase in the PRSs for total cholesterol (OR $0.92,95 \% \mathrm{Cl} 0.85-0.99 ; p=0.03$ ) and LDL cholesterol (OR 0.88; 95\% $\mathrm{Cl}, 0.81-0.95 ; p=0.002$ ) were inversely associated with $\mathrm{ICH}$ risk, no significant associations were found for $\mathrm{HDL}$ and triglycerides (both $\mathrm{p}>0.05$ ). Mendelian Randomization analyses indicated that $1 \mathrm{mmol} / \mathrm{L}$ (38.67 $\mathrm{mg} / \mathrm{dL}$ ) increase of genetically-instrumented total and LDL cholesterol were associated with $23 \%$ (OR $0.77 ; 95 \% \mathrm{Cl} 0.65-0.98 ; p=0.03$ ) and 41\% lower risks of $\mathrm{ICH}(\mathrm{OR} 0.59 ; 95 \% \mathrm{Cl} 0.42-0.82$; $p=0.002)$, respectively.

Interpretation: Genetically elevated LDL levels were associated with lower risk of ICH, providing support for a potential causal role of LDL cholesterol in $\mathrm{ICH}$.

This article is protected by copyright. All rights reserved. 


\section{INTRODUCTION}

Novel therapies are needed for spontaneous, non-traumatic intracerebral hemorrhage (ICH), a disease responsible for $50 \%$ of stroke-related deaths and disability with no proven acute treatments. ${ }^{1}$ Several complementary lines of evidence highlight the importance of lipid metabolism as a promising pathophysiological pathway for risk prediction and therapeutic strategies. The Stroke Prevention by Aggressive Reduction in Cholesterol Levels (SPARCL) trial reported that statin treatment in surviving adults with a first ischemic stroke reduced the risk of recurrent ischemic stroke but increased the risk of $\mathrm{ICH}^{2}$ However, this trial could not exclude possible pleiotropic effects of statins, whereby the effects on $\mathrm{ICH}$ may be independent of the effects of statins on lipids. ${ }^{3}$ In addition, clinical trials investigating statins as the primary cardiovascular disease prevention strategy have yielded inconsistent results for ICH risk. ${ }^{4-6}$

Results from several observational studies evaluating data from thousands of ICH cases also reported inverse associations between lipid levels and $\mathrm{ICH}$ risk. The Genetic and Environmental Risk Factors for Hemorrhagic Stroke (GERFHS) Study reported a one third lower ICH risk among study participants with a past medical history of hypercholesterolemia. ${ }^{7}$ Other observational studies reported that higher low-density lipoprotein cholesterol (LDL-C) levels were correlated with $\mathrm{ICH}$ severity and 3-month clinical outcome. ${ }^{8}$ While promising, these studies are limited by the observational nature of the underlying design, which preclude the possibility of establishing causality. 
Population genetics provides powerful tools to overcome such limitations in causal inference. Genetic variants known to associate with lipid levels can be used as instruments to evaluate the causal relationship between different lipid fractions and risk of $\mathrm{ICH}^{9}{ }^{9}$ These genetic variants are randomly distributed during meiosis and are ought to be exempt from confounding by environmental exposures. ${ }^{9-11} \mathrm{~A}$ recent report from the China Kadoorie Biobank involving several thousand $\mathrm{ICH}$ cases demonstrated concordant effects estimates between the observational and genetic analyses for LDL-C and ICH risk in Chinese adults, thereby providing strong support for the causal relevance for this association in this ethnic group. However, in contrast with highly significant inverse observational associations of directly-measured LDL-C and ICH risk, the associations of genetically-instrumented LDL-C and ICH risk were not statistically significant in this study. ${ }^{12}$

To overcome the limitations of previous randomized trials, observational studies and genetic analyses, we conducted a multistage genetic association study that combined polygenic risk score $^{13}$ (PRS) and Mendelian randomization ${ }^{9}$ (MR) analyses to test the hypothesis that genetically-elevated lipid levels are associated with a lower risk of $\mathrm{ICH}$. We separately evaluated the associations of genetically-instrumented differences in total cholesterol (TC), low-density lipoprotein cholesterol (LDL-C), high-density lipoprotein cholesterol (HDL-C) and triglycerides. Because of the known differences in underlying biology according to the location of $\mathrm{ICH}$ within the brain, we conducted stratified analyses based on hemorrhage location. ${ }^{14}$ 


\section{METHODS}

\section{Study design}

We conducted a three-stage genetic study in participants from European ancestry. All study stages utilized publicly available individual-level data accessible through the National Institute of Health database of Genotypes and Phenotypes and UK Biobank. All studies had approval from the local institutional review board or ethics committee at each participating institution. Informed consent was obtained from all study participants or their legally authorized representatives, or consent was waived via protocol-specific allowance. All study participants had available genomewide genotyping data, allowing the implementation of principal component analysis to confirm ancestry and account for population stratification. In stage 1, we constructed four PRSs for TC, LCL-C, HDL-C and triglycerides using genetic variants known to associate with each of these traits in previous studies. ${ }^{15-17}$ We estimated the effect of each PRS on its corresponding lipid trait using data from the UK Biobank. In stage 2, we conducted an individual participant data metaanalysis of genetic studies of $\mathrm{ICH}$ to evaluate the association between the four PRSs created in stage 1 and risk of $\mathrm{ICH}$. This stage included individual-level data from three case-control genetic studies: the Genetics of Cerebral Hemorrhage on Anticoagulation (GOCHA) Study, ${ }^{18}$ International Stroke Genetics Consortium ICH Study (ISGC-ICH), ${ }^{19}$ and the Genetic and Environmental Risk Factors for Hemorrhagic Stroke (GERFHS) Study. ${ }^{7}$ In stage 3, we combined the effect estimates

from stage 1 (associations between each PRS and its corresponding lipid fraction) and stage 2 (associations between each PRS and $\mathrm{ICH}$ risk) to conduct MR analyses of geneticallyinstrumented lipid levels and $\mathrm{ICH}$ risk. 


\section{Blood lipids in the UK Biobank}

Stage 1 utilized data from the UK Biobank, a prospective population-based cohort study that recruited 500,000 community-dwelling individuals aged 40 to 69 years between 2006 and 2010 from across the United Kingdom. Study participants undergone multiple baseline physical measures, provided blood, urine and saliva samples for different analysis, provided detailed information about themselves, and agreed to have their health followed. ${ }^{20}$ We used recently released values for lipid traits which were measured using a Beckman Colter AU5800 clinical chemistry analyzer. Analyzer performance was verified continually throughout the project.

\section{Ascertainment of ICH cases and ICH-free controls}

$\mathrm{ICH}$ cases included in Stage 2 were defined as new and acute (<24hours) neurological deficits with consistent findings in neuroimaging. Cases were aged $>55$ years in GOCHA, and $>18$ years in GERFHS and the ISGC-ICH. Patients were excluded if they were taking anticoagulants (antiaggregants were permitted) or had head trauma, hemorrhagic conversion of an ischemic stroke, intracerebral tumor, intracerebral vascular malformation, vasculitis, or any other cause of secondary $\mathrm{ICH}$. Controls included in Stage 2 were $\mathrm{ICH}$-free individuals enrolled at the same study sites as cases and followed the same age and ethnicity criteria. Controls were sampled by random digit dialing in GERFHS and by random selection from ambulatory clinics in GOCHA and ISGC$\mathrm{ICH}$.

\section{Neuroimaging analysis}

This article is protected by copyright. All rights reserved. 
For ICH cases included in Stage 2, stroke neurologists or neuroradiologists at each participating site confirmed the diagnosis and, following the known differences in underlying biology, classified each case as lobar or nonlobar according to location. ${ }^{21} \mathrm{ICH}$ originating in the corticosubcortical junction was defined as lobar, whereas $\mathrm{ICH}$ selectively involving the thalamus, internal capsule, basal ganglia, brainstem, or cerebellum was defined as nonlobar.

\section{Genetic data}

Study participants were genotyped using the UK Biobank Axiom Array (UK Biobank Study), Illumina HumanHap610-Quad (GOCHA and ISGC-ICH), and Affymetrix 6.0 (GERFHS). Standard quality control procedures ${ }^{22}$ were implemented separately for each participating study. SNPs with palindromic alleles (A/T or $C / G)$, a genotype call rate $<95 \%$, significant difference in missingness between cases and controls $(p<0.05)$, deviation from Hardy-Weinberg Equilibrium $\left(p<1 \times 10^{-6}\right)$, or minor allele frequency (MAF) $<1 \%$ were removed. Individuals with a genotype call rate $<95 \%$, inconsistency between self-reported and genotyped sex, an inferred first or second degree relative in the sample, and a genome-wide heterozygosity F-statistic greater than five times the standard deviation were filtered out from the analysis. Principal component analysis was implemented to account for population structure. ${ }^{23}$ After quality control and principal component analyses, genetic data were prephased and imputed to 1000 Genomes integrated reference panels (Phase 3 integrated variant set release in NCBI build 37). ${ }^{24}$ Post-imputation filters included MAF $<1 \%$, an information score $<0.7$, and missing estimates in one or more studies.

\section{Statistical analyses}

This article is protected by copyright. All rights reserved. 
We present discrete variables as counts (percentage) and continuous variables as mean (standard deviation [SD]) or median (interquartile range [IQR]), as appropriate.

Stage 1. Derivation of lipid-related PRSs. We used PRSs to model each individual's genetic load of lipid-related risk alleles. To build these PRSs, we queried the GWAS Catalog and reviewed published genome-wide association studies of lipids. ${ }^{15-17}$ Following similar recent analyses, we selected independent $\left(r^{2}<0.3\right)$ and common (MAF>5\%) single nucleotide polymorphisms (SNPs) associated with at least one lipid trait at $p<5 \times 10^{-8} \cdot{ }^{15}$ All selected SNPs were aligned to the GRCh37 assembly of the human genome and, for each SNP, the allele associated with an increase in lipid levels was identified and utilized as the tested allele in downstream analyses. The epsilon variants within APOE were not included in these PRSs, as they are not captured by commercially available genotyping arrays and there is a plausible alternative pathway via cerebral amyloid angiopathy that could mediate its association with $\mathrm{ICH} .{ }^{25}$ The PRS for each individual is the sum of the product of the risk allele counts for each locus multiplied by the allele's reported effect on the corresponding lipid level. To assure common directionality of effects, the allele associated with higher lipid levels was selected as the effect allele during scoring. One PRS per lipid trait was generated (TC, LDL-C, HDL-C and triglycerides). All four PRSs were standardized (by subtracting the mean and dividing by the SD) and entered as continuous predictors into regression models. With this approach, the beta for the PRS can be interpreted as the change in $\mathrm{ICH}$ risk per $1 \mathrm{SD}$ increase of the PRS. The association between each PRS and its corresponding lipid trait was evaluated using linear regression, adjusting for age, sex, and principal components 1 to 4 . The primary analysis was restricted to unrelated study participants of geneticallydetermined European ancestry who were not taking lipid-lowering medications. In secondary 
analyses, we followed a less restrictive approach and included all study participants of selfreported European ancestry.

Stage 2. Association between each PRS and ICH risk. We evaluated the association between each PRS and risk of ICH via logistic regression adjusting for age, sex and principal components 1 to 4 . Analyses were completed separately in each genetic study and pooled in meta-analysis using fixed-effects (primary analysis) and random effects (secondary analysis) approaches with evaluation of heterogeneity via Cochrane's $Q$ (with corresponding $p$ ) and $I^{2}$. In sensitivity analyses, we excluded genetic variants within CETP, a locus that powerfully modifies lipid levels previously shown to be associated with $\mathrm{ICH}$ risk. To account for recognized differences in underlying causative $\mathrm{ICH}$ mechanism by location within the brain, lipid traits with significant associations were taken forward to stratified analyses based on hemorrhage location (lobar or nonlobar).

Stage 3. Mendelian randomization analyses. The causal relationship between geneticallydetermined lipid levels and $\mathrm{ICH}$ risk was evaluated via MR analyses using each PRS as an instrument. The primary MR analysis utilized the ratio method combining the point estimates and standards errors from Stage 1 (denominator) and Stage 2 (numerator). In secondary analyses, we implemented other MR methods usually used with summary level data, including inversevariance weighted, weighted median, MR-Egger, and Mendelian Randomization Pleiotropy Residual Sum and Outlier (MR-PRESSO) analyses. To confirm the validity of our results, we implemented MR analyses of genetically-instrumented cholesterol levels and risk of ischemic stroke using estimates for lipids levels from the UK Biobank and estimates for ischemic stroke 
risk from the MEGASTROKE ${ }^{26}$ consortium; these results were compared with previously reported MR studies for the same analysis.

Software. We used the GWAS Catalog to identify genetic variants related to lipid levels, PLINK for quality control procedures and generation of PRSs, ${ }^{27}$ EIGENSTRAT for principal component analysis, ${ }^{28}$ SHAPEIT for genotype prephasing, ${ }^{29}$ IMPUTE2 for imputation, ${ }^{30}$ and Rstudio (Version1.1.453) for association testing, meta-analysis, and MR analysis. ${ }^{31}$

This article is protected by copyright. All rights reserved. 
RESULTS. Selected population characteristics are presented in Table 1.

\section{Stage 1: Derivation of cholesterol-related PRSs}

We identified 1,459 common (MAF >5\%) genetic variants reported by prior studies as strongly associated with one or more of the lipid traits of interest. These common variants included 410 SNPs for TC, 339 for LDL-C, 393 for HDL-C and 317 for triglycerides (Supplementary Tables 14). We built four different PRSs, one for each lipid trait, and evaluated their associations with their corresponding trait in the UK Biobank. All four PRSs showed highly significant associations with their corresponding lipid trait, both in the primary analysis considering 316,428 (mean age 68 [SD 8], 170,871 females [54\%]) unrelated individuals of European ancestry not on lipid-lowering medications (all $p<1 \times 10^{-100}$ ), and in the secondary analysis not applying any exclusion criteria (all $\mathrm{p}<1 \times 10^{-100} ;$ Table 2).

\section{Stage 2: Association between each PRS and ICH risk}

A total of 1,286 ICH cases (mean age 71 [SD 13], 593 females [46\%]) and 1,261 ICH-free controls (mean age 68 [SD 14], 613 females [49\%]) from the GOCHA, ISGC ICH, and GERFHS studies were included in association testing (Table 1). For TC, each additional SD increase of the corresponding PRS was associated with an $8 \%$ lower $\mathrm{ICH}$ risk (OR 0.92, 95\% $\mathrm{Cl} 0.85-0.99$; $p=0.03)$. When evaluating specific lipid fractions, we found that each additional SD increase of the LDL-C- based PRS was associated with a $12 \%$ lower risk of ICH (OR 0.88, 95\% $0.81-0.95$; $p=0.002$ ) (Table 3). Similar results were obtained when utilizing random-effects meta-analyses.

This article is protected by copyright. All rights reserved. 
These associations remained significant after removing CETP (Table 4). We did not find significant associations for the PRSs based on HDL-C or triglycerides (both $p>0.05$ ).

\section{Stage 3: Mendelian randomization analysis}

The primary MR analysis implemented the ratio method utilizing the effect estimates obtained in Stages 1 and 2. As shown in Table 5, each $1 \mathrm{mmol} / \mathrm{L}$ (or $38.67 \mathrm{mg} / \mathrm{dL}$ ) increase of geneticallyinstrumented TC was associated with a $23 \%$ reduction of $\mathrm{ICH}$ risk $(\mathrm{OR} 0.77,95 \% \mathrm{Cl} 0.60-0.98$; $p=0.03$ ), whereas a $1 \mathrm{mmol} / \mathrm{L}$ (or $38.67 \mathrm{mg} / \mathrm{dL}$ ) increase of genetically-instrumented LDL-C was associated with a $41 \%$ reduction in this risk (OR $0.59,95 \% \mathrm{Cl} 0.42-0.82 ; p=0.002)$. These results remained unaltered when the effect of each PRS on its corresponding lipid trait was estimated without excluding any individuals from the UK Biobank (data not shown). Secondary analyses utilizing an $r^{2}<0.1$ yielded comparable results for LDL-C (OR $\left.0.62,95 \% \mathrm{Cl} 0.41-0.94 ; p=0.02\right)$ and confirmed the direction of effect for TC without reaching statistical significance (OR $0.94,95 \% \mathrm{Cl}$ 0.87-1.02; $p=0.17)$. Secondary analyses utilizing other MR methods confirmed the direction of effect, although not all yielded statistical significance (Table 5). There was no indication of pleiotropy for either TC or LDL-C (MR-egger intercepts and MR-PRESSO global test $p>0.05$ ). MR analyses for LDL-C and risk of ischemic stroke utilizing the estimates for LDL-C from the UK Biobank yielded similar results to those reported by prior publications based on lipid estimates from the Global Lipid Genetics Consortium (Table 6).

\section{Stratification based on location of the ICH within the brain}

This article is protected by copyright. All rights reserved. 
A total of $1,243 \mathrm{ICH}$ cases (96\%) had available information about the location of the hematoma within the brain. Of these, 539 (43\%) had lobar ICH and 704 (56\%) had nonlobar ICH. Locationspecific analyses indicated that the association between the LDL-C PRS and ICH risk remained significant for both lobar (OR 0.81, 95\% $\mathrm{Cl} 0.73-0.89 ; p<0.001)$ and nonlobar ICH (OR 0.90, 95\% $0.82-0.99 ; p=0.04$ - Table 7), whereas the association between ICH risk and the TC PRS was significant for lobar (OR 0.89, 95\% Cl $0.80-0.99 ; p=0.03$ ) but not nonlobar bleeds (OR 0.94, $95 \% \mathrm{Cl} 0.85-1.08 ; p=0.20)$. Mendelian randomization analyses implementing the ratio method using these location-specific estimates indicated that genetically-elevated LDL-C was associated with a decreased risk of ICH for both lobar (OR 0.41, 95\% CI 0.27-0.64; $p<0.001$ ) and nonlobar $\mathrm{ICH}(\mathrm{OR} 0.66,95 \% \mathrm{Cl} 0.44-0.97 ; p=0.04)$, whereas genetically elevated TC was associated with a decreased risk of lobar (OR $0.70,95 \% \mathrm{Cl} 0.51-0.96 ; p=0.03)$ but not nonlobar ICH (OR 0.73, $95 \% \mathrm{Cl} 0.62-1.11 ; p=0.20)$.

This article is protected by copyright. All rights reserved. 


\section{DISCUSSION}

We report the results of a multi-stage genetic association study that evaluated whether genetically-instrumented levels of different lipid traits influence the risk of spontaneous ICH. We constructed four PRSs to model the aggregate genetic load of risk alleles for TC, LDL-C, HDL-C and triglycerides; assessed for association between each PRS and its corresponding lipid trait; assessed for association between each PRS and ICH risk; and utilized the estimates obtained in prior steps to conduct MR analyses. We found that all four PRSs were robustly associated with their corresponding lipid trait and that the PRSs for TC and LDL-C were inversely associated with $\mathrm{ICH}$ risk. Analyses stratified by location indicated that these associations remained significant for both lobar and nonlobar $\mathrm{ICH}$, with stronger associations for lobar bleeds. Of note, the geneticallyinstrumented HDL-C and triglycerides levels were not associated with $\mathrm{ICH}$ risk.

Previous studies provided promising, but inconclusive, evidence on the relevance of LDL-C for risk of $\mathrm{ICH}$. The evidence from randomized control trials of statins is inconsistent. The SPARCL trial, a study focused on the utilization of statins for secondary prevention after a first stroke or transient ischemic attack, found an unexpected increment in $\mathrm{ICH}$ risk as a side effect. ${ }^{2}$ However, large meta-analyses of statin trials yielded conflicting conclusions for this question, with some finding similar associations $s^{5,12}$ and others finding nulls results. ${ }^{4}$ This inconsistencies may be driven by a lack of statistical power, as $\mathrm{ICH}$ is a rare event and statin trials, while large, do not accrue the necessary number of events to appropriately evaluate this relationship. From an observational perspective, the Genetic and Environmental Risk Factors for Hemorrhagic Stroke Study reported a reduction in $\mathrm{ICH}$ risk among study participants with a history of hypercholesterolemia. ${ }^{7}$ In terms

This article is protected by copyright. All rights reserved. 
of genetic evidence, a candidate gene study focused on the powerful lipid regulatory gene CETP found an association between variants at this locus and $\mathrm{ICH}$ risk ${ }^{32}$ While promising, each of these pieces of evidence has an important limitation: the inconsistency of results observed in clinical trials of statin treatment, the inability to draw causal conclusions in observational studies, and the and the single-locus design nature of the CETP study.

The present study provides important additional evidence to support a causal role of LDL-C cholesterol in risk of $\mathrm{ICH}$. Genetic variants known to be associated with lipid levels can be used as instruments to evaluate a causal relationship between different lipid fractions and $\mathrm{ICH}$ risk. ${ }^{33}$ We deployed two specific strategies to maximize the accuracy and power of this analytical strategy. First, all analytical steps used individual level phenotypic and genotypic data, permitting the utilization of rigorous quality control procedures and the implementation of sensitivity analyses to evaluate whether results were robust to different modeling strategies. Second, we estimated the effect of our instruments, the four lipid-related PRSs, on newly released data on lipid fractions from the UK Biobank. The sample size of this study $(400,000+$ study participants) maximizes the discovery power of the MR analysis by improving the precision of the estimates.

Beyond providing support for a causal role of lipid metabolism in $\mathrm{ICH}$ in Europeans, our results also support a specific role of LDL-C as the operative lipid trait mediating the observed inverse associations. Previous studies in Asians, who have lower LDL-C levels than Western populations, reported that this lipid fraction is the likely mediator underlying the inverse association between TC and $\mathrm{ICH}$ risk. A nested case-control study within the prospective China Kadoorie Biobank 
involving $\sim 5,000 \mathrm{ICH}$ cases reported that elevated levels of LDL-C were inversely associated with risk of $\mathrm{ICH}^{12}$ Mendelian randomization analyses in this study yielded concordant effect estimates, although these were not statistically significant, possibly due to the lower number of SNPs utilized to build the instrument (59 variants) and the European origin of the populations where these lipid-related SNPS had originally been identified. Our results confirm the role of LDLC as the mediating lipid fraction and provide evidence supporting its role in persons of European ancestry. We acknowledge that, while concordant in the direction of effect, the point estimates for the MR analysis of LDL-C and ICH risk yielded by the present study (OR $0.59,95 \% \mathrm{CI} 0.42-0.82)$ are significantly more extreme than those reported in the China Kadoorie Biobank (OR 0.89, $95 \% \mathrm{Cl}$ 0.62-1.16). The discrepant results could reflect the lower mean age at ICH onset and lower mean LDL-C levels in Chinese compared with Europeans or between-population differences in the distribution of LDL-C which could have biased such comparisons. While the overlap in confidence intervals between European and Chinese studies indicate that differences in the estimates between studies are not statistically significant, precise estimates of effects of LDL-C on $\mathrm{ICH}$ risk will require additional analyses in further studies involving larger numbers of $\mathrm{ICH}$ cases.

The independent replication of our findings constitutes an important next step to consolidate lipid metabolism as an actionable biological target in $\mathrm{ICH}$. This follow-up studies will be greatly facilitated by increasingly available data from large biobanks and multi-purpose repositories like $\mathrm{dbGaP}^{34}$ and the European Genome-phenome Archive (EGA). ${ }^{35}$ Another important future direction involves the clarification of the pathophysiology underlying the observed association.

This article is protected by copyright. All rights reserved. 
Histopathological evidence in humans suggests that lower cholesterol concentrations may increase the frailty and permeability of brain vessel walls, triggering arterionecrosis, microaneurysm formation and, ultimately, $\mathrm{ICH}^{36,37}$ Because our findings point to an effect that is present for both lobar and deep hemorrhages, it is possible that low lipid levels could work as an effect modifier of the risk conveyed by the underlying small vessel disease responsible for the bleed.

The results of this study prompt questions about the risk-benefit ratio of lowering LDL cholesterol for risk of different stroke types. The China Kadoorie Biobank demonstrated equal and opposite proportional differences in risk of ischemic stroke and ICH for equivalent differences in LDL-C cholesterol. Because the absolute number of ischemic stroke cases exceeded those of ICH by 4fold, any beneficial effects of lowering LDL-C on ischemic stroke were likely to outweigh risks of $\mathrm{ICH}$. In light of this evidence, it is reasonable to use extreme caution when evaluating possible applications of these results to clinical decision-making.

An important limitation of our study was the inability to evaluate the effect of other lipid fractions. Alongside the vast majority of related studies, we evaluated TC, LDL-C, HDL-C and triglycerides, the four lipid traits routinely used in clinical practice, and did not account for several other cardiovascular risk-stratifying lipid fractions, such as apolipoprotein levels. ${ }^{38-40}$ A second important limitation is the absence of an independent dataset to replicate the association analysis between the lipid-related PRS and $\mathrm{ICH}$ risk. The relatively low incidence of $\mathrm{ICH}$ in Western populations limits the amount of appropriately ascertained cases within available genetic and 
location information. Nevertheless, the estimates observed in three different genetic studies of $\mathrm{ICH}$ were consistent with each other. In addition, because this study was not intended at risk loci discovery, it could be argued that independent replication for this specific analysis is not strictly needed. Finally, the limited available data on medical history and use of medication in ICH cases precluded any detailed analysis of possible interactions or confounding effects by these variables.

\section{SUMMARY}

In conclusion, we report an inverse association between the genetic load of risk alleles for total and LDL-C and risk of ICH in persons of European ancestry. We also found that geneticallyinstrumented higher total and LDL-C were inversely associated with this same risk. Similar associations were observed for both lobar and nonlobar $\mathrm{ICH}$. Our results support a potential causal role of LDL-C in risk of primary, non-traumatic ICH. ACKNOWLEDGEMENTS GJF receives grant support from the National Institutes of Health (K76AG059992 and R03NS112859), the American Heart Association (18IDDG34280056), the Yale Pepper Scholar Award (P30AG021342) and the Neurocritical Care Society Research Fellowship. TMG receives grant support from the National Institutes of Health (P30AG021342, K07AG043587). JFM receives grant support from the Earl \& Nyda Swanson Neurosciences Research Fund and the Harley N. and Rebecca N. Hotchkiss Endowed Fund in Neuroscience Research honoring Ken and Marietta. CLP receives grant support from the American Heart Association (19CDA34620004). MS receives grant support from the National Institutes of Health (U01NS074425, U01NS102289). MH receives grant support by the British Heart Foundation Intermediate Clinical Research Fellowship (FS/18/23/33512) and the National Institute for Health 
Research Oxford Biomedical Research Centre and works in a unit that receives grant support from the UK Medical Research Council. SM receives grant support from the American Heart Association/American Stroke Association fellowship (18POST34080063). MVH is supported by the British Heart Foundation (FS/18/23/33512) and the National Institute for Health Research Oxford Biomedical Research Centre. DW receives grant support from the National Institutes of Health (U24NS107200, R01NS100417). JR receives grant support from the National Institutes of Health (R24NS092983, R01NS093870, T32NS100663, R01NS100417). KNS receives grant support from the National Institutes of Health (R03NS112859, U24NS107136, U24NS107215, R01NR018335) and American Heart Association (17CSA33550004). CDA receives grant support from the National Institutes of Health (K23NS086873, R01NS103924), the American Heart Association (18SFRN34250007), the MGH Center for Genomic Medicine, and research grants from Bayer AG, and had has consulted for ApoPharma, Inc.

\section{AUTHOR CONTRIBUTIONS}

Conception and design of the study: GJF, DG, MG, LS, TMG, SK, CDL, DW, JR, KNS and CDA.

Acquisition and analysis of data: GJF, EK, JNA, RBN, AL, SM, JC, MS, JFM, DLB, BBW, DLT, JMJ, HS, JJC, IFC, AL, AS, CLP, NHP, CNM and AB.

Drafting the text and preparing the figures: GJF, MH, DB, ZC, LLS, RC, RGW and CDA.

This article is protected by copyright. All rights reserved. 


\section{POTENTIAL CONFLICTS OF INTEREST}

None.

\section{DATA SHARING}

All data utilized in this study is publicly available through dbGaP

(https://www.ncbi.nlm.nih.gov/gap/) and the UK Biobank (https://www.ukbiobank.ac.uk/).

This article is protected by copyright. All rights reserved. 


\section{REFERENCES}

1 An SJ, Kim TJ, Yoon B-W. Epidemiology, Risk Factors, and Clinical Features of Intracerebral Hemorrhage: An Update. J Stroke 2017; 19: 3-10.

2 Goldstein LB, Amarenco P, Szarek M, et al. Hemorrhagic stroke in the Stroke Prevention by Aggressive Reduction in Cholesterol Levels study. Neurology 2008; 70: 2364 LP - 2370.

3 Liao JK, Laufs U. Pleiotropic effects of statins-NIH Public Access. Annu Rev Pharmacol Toxicol 2009; : 28.

4 McKinney JS, Kostis WJ. Statin Therapy and the Risk of Intracerebral Hemorrhage. Stroke 2012; 43: 2149-56.

5 Pandit AK, Kumar P, Kumar A, Chakravarty K, Misra S, Prasad K. High-dose statin therapy and risk of intracerebral hemorrhage: A meta-analysis. Acta Neurol. Scand. 2016; 134: $22-$ 8.

6 Brown MJ. MRC/BHF Heart Protection Study. Lancet. 2002; 360. DOI:10.1016/S01406736(02)11690-4.

7 Woo D, Sauerbeck LR, Kissela BM, et al. Genetic and Environmental Risk Factors for Intracerebral Hemorrhage. Stroke 2002; 33: 1190-6.

8 Rodriguez-Luna D, Rubiera M, Ribo M, et al. Serum Low-Density Lipoprotein Cholesterol Level Predicts Hematoma Growth and Clinical Outcome After Acute Intracerebral Hemorrhage. Stroke 2011; 42: 2447-52.

9 Smith GD, Ebrahim S. Mendelian Randomization: Genetic Variants as Instruments for Strengthening Causal Inference in Observational Studies. In: Biosocial Surveys. 2008: 7895.

10 Falcone GJ, Biffi A, Devan WJ, et al. Burden of blood pressure-related alleles is associated with larger hematoma volume and worse outcome in intracerebral hemorrhage. Stroke 2013; 44: 321-6.

11 Lewis CM, Vassos E. Prospects for using risk scores in polygenic medicine. Genome Med 2017; 9: 96.

12 Sun L, Clarke R, Bennett D, et al. Causal associations of blood lipids with risk of ischemic stroke and intracerebral hemorrhage in Chinese adults. Nat. Med. 2019. DOI:10.1038/s41591-019-0366-X.

13 Smith JA, Ware EB, Middha P, Beacher L, Kardia SLR. Current Applications of Genetic Risk Scores to Cardiovascular Outcomes and Subclinical Phenotypes. Curr Epidemiol reports; 2: 180-90.

14 Martini SR, Flaherty ML, Brown WM, et al. Risk factors for intracerebral hemorrhage differ according to hemorrhage location. Neurology 2012; 79: 2275-82.

15 Hoffmann TJ, Theusch E, Haldar T, et al. A large electronic-health-record-based genome-

This article is protected by copyright. All rights reserved. 
wide study of serum lipids. Nat Genet 2018; 50: 401-13.

16 Klarin D, Damrauer SM, Cho K, et al. Genetics of blood lipids among $\sim 300,000$ multi-ethnic participants of the Million Veteran Program. Nat Genet 2018; 50: 1514-23.

17 Consortium GLG, Willer CJ, Schmidt EM, et al. Discovery and refinement of loci associated with lipid levels. Nat Genet 2013; 45: 1274.

18 Genes for Cerebral Hemorrhage on Anticoagulation Collaborative G. Exploiting common genetic variation to make anticoagulation safer. Stroke 2009; 40: S64-6.

19 Woo D, Falcone GJ, Devan WJ, et al. Meta-analysis of genome-wide association studies identifies 1q22 as a susceptibility locus for intracerebral hemorrhage. Am J Hum Genet 2014; 94: 511-21.

20 Cox N. UK Biobank shares the promise of big data. Nature 2018; 562: 194-5.

21 Falcone GJ, Woo D. Genetics of Spontaneous Intracerebral Hemorrhage. Stroke 2017; 48: 3420-4.

22 Marees AT, de Kluiver $\mathrm{H}$, Stringer $\mathrm{S}$, et al. A tutorial on conducting genome-wide association studies: Quality control and statistical analysis. Int J Methods Psychiatr Res 2018; 27. DOI:10.1016/j.taml.2017.02.002.

23 Price AL, Patterson NJ, Plenge RM, Weinblatt ME, Shadick NA, Reich D. Principal components analysis corrects for stratification in genome-wide association studies. Nat Genet 2006; 38: 904.

24 The 1000 Genomes Project Consortium. Supplementary Information for 'A map of human genome variation from population-scale sequencing.' Nature 2010; 467: 1061-73.

25 Biffi A, Sonni A, Anderson CD, et al. Variants at APOE influence risk of deep and lobar intracerebral hemorrhage. Ann Neurol 2010; 68: 934-43.

26 Malik R, Chauhan G, Traylor M, et al. Multiancestry genome-wide association study of 520,000 subjects identifies 32 loci associated with stroke and stroke subtypes. Nat Genet 2018; 50: 524-37.

27 Purcell S, Neale B, Todd-Brown K, et al. PLINK: a tool set for whole-genome association and population-based linkage analyses. Am J Hum Genet 2007; 81: 559-75.

28 Wu C, Dewan A, Hoh J, Wang Z. A Comparison of Association Methods Correcting for Population Stratification in Case-Control Studies. Ann Hum Genet 2011; 75: 418-27.

29 Howie B, Fuchsberger C, Stephens M, Marchini J, Abecasis GR. Fast and accurate genotype imputation in genome-wide association studies through pre-phasing. Nat Genet 2012; 44: 955-9.

30 Howie BN, Donnelly P, Marchini J. A flexible and accurate genotype imputation method for the next generation of genome-wide association studies. PLoS Genet 2009; 5. DOI:10.1371/journal.pgen.1000529.

31 RStudio Team -. RStudio: Integrated Development for R. [Online] RStudio, Inc, Boston, MA 
URL http//www rstudio com 2015; : RStudio, Inc., Boston, MA.

32 Anderson CD, Falcone GJ, Phuah C-L, et al. Genetic variants in CETP increase risk of intracerebral hemorrhage. Ann Neurol 2016; 80: 730-40.

33 Allman PH, Aban IB, Tiwari HK, Cutter GR. An introduction to Mendelian randomization with applications in neurology. Mult. Scler. Relat. Disord. 2018. DOI:10.1016/j.msard.2018.06.017.

34 Tryka KA, Hao L, Sturcke A, et al. NCBl's database of genotypes and phenotypes: DbGaP. Nucleic Acids Res 2014; 42. DOI:10.1093/nar/gkt1211.

35 Lappalainen I, Almeida-King J, Kumanduri V, et al. The European Genome-phenome Archive of human data consented for biomedical research. Nat. Genet. 2015; 47: 692-5.

36 Ooneda G, Yoshida Y, Suzuki K, et al. Smooth muscle cells in the development of plasmatic arterionecrosis, arteriosclerosis, and arterial contraction. J Vasc Res 1978; 15: 148-56.

37 Bang OY, Saver JL, Liebeskind DS, et al. Cholesterol level and symptomatic hemorrhagic transformation after ischemic stroke thrombolysis. Neurology 2007; 68: 737-42.

38 Contois JH, McConnell JP, Sethi AA, et al. Apolipoprotein B and cardiovascular disease risk: Position statement from the AACC lipoproteins and vascular diseases division working group on best practices. Clin Chem 2009; 55: 407-19.

39 Ryoo JH, Ha EH, Kim SG, Ryu S, Lee DW. Apolipoprotein B is highly associated with the risk of coronary heart disease as estimated by the framingham risk score in healthy Korean men. J Korean Med Sci 2011; 26: 631-6.

40 Upadhyay RK. Emerging Risk Biomarkers in Cardiovascular. J Lipids 2015; 2015.

This article is protected by copyright. All rights reserved. 


\section{Please wait...}

If this message is not eventually replaced by the proper contents of the document, your PDF viewer may not be able to display this type of document.

You can upgrade to the latest version of Adobe Reader for Windows®, Mac, or Linux® by visiting http://www.adobe.com/go/reader_download.

For more assistance with Adobe Reader visit http://www.adobe.com/go/acrreader.

Windows is either a registered trademark or a trademark of Microsoft Corporation in the United States and/or other countries. Mac is a trademark
of Apple Inc., registered in the United States and other countries. Linux is the registered trademark of Linus Torvalds in the U.S. and other countries. 
Table 1. Studies included in this analysis.

\begin{tabular}{|c|c|c|c|c|}
\hline Characteristic & UK Biobank & GOCHA & ISGC ICH Study & GERFHS \\
\hline Analytical stage & $\begin{array}{c}\text { Association } \\
\text { Cholesterol level } \sim \text { PRS }\end{array}$ & $\begin{array}{c}\text { Association } \\
\text { ICH Risk PRS }\end{array}$ & $\begin{array}{c}\text { Association } \\
\text { ICH Risk PRS }\end{array}$ & $\begin{array}{c}\text { Association } \\
\mathrm{ICH} \text { Risk PRS }\end{array}$ \\
\hline Study design & Cohort & Case / Control & Case / Control & Case / Control \\
\hline Study participants & 316,428 & $277 / 248$ & $563 / 523$ & $446 / 490$ \\
\hline Age, mean (SD) & $68(8)$ & $73(10) / 72(8)$ & 71 (14) / 66 (16) & 70 (14) / 68 (13) \\
\hline Female sex $n, \%$ & $170,871(54)$ & $130(47) / 123(50)$ & $252(45) / 255(49)$ & $211(47) / 235(48)$ \\
\hline Genotyping platform & $\begin{array}{c}\text { Affymetrix } \\
\text { UK Biobank array }\end{array}$ & $\begin{array}{c}\text { Illumina } \\
\text { HumanHap550 }\end{array}$ & $\begin{array}{c}\text { Illumina } \\
\text { HumanHap550 }\end{array}$ & Affymetrix 6.0 \\
\hline Genotyped SNPs & 820,967 & 527,508 & 527,508 & 580,491 \\
\hline Imputed SNPs & $73,355,667$ & $7,965,700$ & $7,965,700$ & $7,967,430$ \\
\hline
\end{tabular}

Acronyms: UK: United Kingdom; GOCHA: Genetics of Cerebral Hemorrhage with Anticoagulation; ISGC: International Stroke Genetics Consortium; GERFHS: Genetic and Environmental Risk Factors for Hemorrhagic Stroke; ICH: intracerebral hemorrhage; PRS: polygenic risk score; SNPs (single nucleotide polymorphisms); SD: standard deviation. 
Table 2. Association results for 4 PRS with their corresponding trait in the UK Biobank.

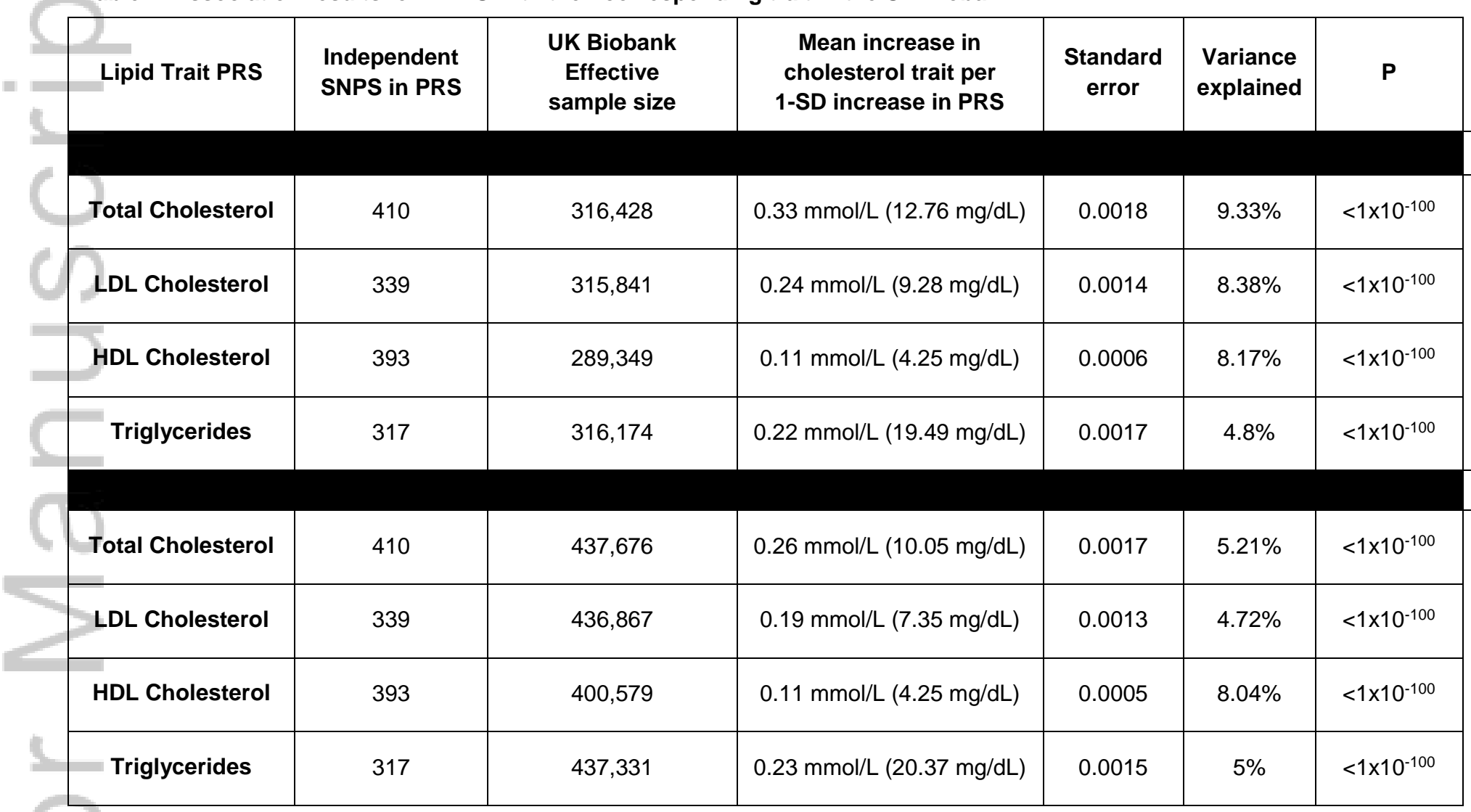

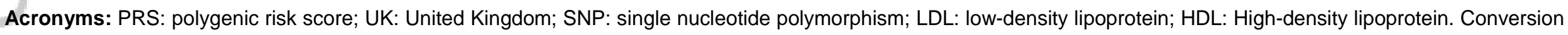
of $\mathrm{mmol} / \mathrm{L}$ to $\mathrm{mg} / \mathrm{dL}$ : for TC, $\mathrm{LDL}$ and $\mathrm{HDL} 1 \mathrm{mmol} / \mathrm{L}=38.67 \mathrm{mg} / \mathrm{dL}$; for triglycerides, $1 \mathrm{mmol} / \mathrm{L}=88.57 \mathrm{mg} / \mathrm{dL}$.

The primary analysis was restricted to unrelated study participant of genetically-determined European ancestry who were not taking lipid-lowering medications.

** The secondary analysis included all study participants of self-reported European ancestry without any other filters.

This article is protected by copyright. All rights reserved. 
Table 3: Study-specific and metanalysis of logistic regression results modeling ICH risk as a function of different PRS.

\begin{tabular}{|c|c|c|c|c|c|c|c|c|}
\hline \multirow{2}{*}{ Study } & \multicolumn{2}{|c|}{ Total Cholesterol } & \multicolumn{2}{|c|}{ LDL Cholesterol } & \multicolumn{2}{|c|}{ HDL Cholesterol } & \multicolumn{2}{|c|}{ Triglycerides } \\
\hline & OR (95\% Cl) & $\mathbf{P}$ & OR (95\% Cl) & $\mathbf{P}$ & OR (95\% Cl) & $\mathbf{P}$ & OR (95\% Cl) & $\mathbf{P}$ \\
\hline GOCHA & $0.95(0.80-1.14)$ & 0.59 & $0.93(0.78-1.11)$ & 0.41 & $1.12(0.94-1.34)$ & 0.20 & $0.95(0.80-1.14)$ & 0.59 \\
\hline ISGC ICH & $0.93(0.82-1.05)$ & 0.24 & $0.88(0.77-0.99)$ & 0.04 & $1.15(1.01-1.30)$ & 0.03 & $1.01(0.89-1.14)$ & 0.84 \\
\hline GERFHS & $0.88(0.77-1.01)$ & 0.07 & $0.85(0.75-0.97)$ & 0.02 & $0.99(0.86-1.12)$ & 0.84 & $1.19(1.04-1.36)$ & $\begin{array}{c}0.00 \\
9\end{array}$ \\
\hline $\begin{array}{l}\text { Fixed effects } \\
\text { Meta-analysis }\end{array}$ & $0.92(0.85-0.99)$ & 0.03 & $0.88(0.81-0.95)$ & 0.002 & $1.10(1.00-1.21)$ & 0.06 & $1.11(0.98-1.23)$ & 0.14 \\
\hline $\begin{array}{l}\text { Random Effects } \\
\text { Meta-analysis }\end{array}$ & $0.92(0.84-0.99)$ & 0.03 & $0.88(0.81-0.95)$ & 0.002 & $1.08(0.98-1.19)$ & 0.13 & $1.05(0.93-1.20)$ & 0.42 \\
\hline Heterogeneity & $1^{2}=0 \%$ & 0.77 & $1^{2}=0 \%$ & 0.75 & $I^{2}=32 \%$ & 0.23 & $\mathrm{I}^{2}=60 \%$ & 0.08 \\
\hline
\end{tabular}

Acronyms: ICH: intracerebral hemorrhage; PRS (polygenic risk score); LDL: low-density lipoprotein; HDL: high-density lipoprotein; Cl: confidence interval; GOCHA: Genetics of Cerebral Hemorrhage with Anticoagulation; ISGC: International Stroke Genetics Consortium; GERFHS: Genetic and Environmental Risk Factors for Hemorrhagic Stroke; FE: Fixed-Effects. RE: Random effects. Het-p: heterogeneity$p$ for the metanalysis. 
Table 4: Metanalysis of logistic regression results modeling ICH risk as a function of different PRS, excluding CETP variants.

\begin{tabular}{|c|c|c|}
\hline Lipid PRS & OR (95\% Cl) & P \\
\hline Total Cholesterol & $0.91(0.84-0.99)$ & 0.03 \\
\hline LDL Cholesterol & $0.88(0.81-0.96)$ & 0.003 \\
\hline HDL Cholesterol & $1.12(0.99-1.21)$ & 0.08 \\
\hline Triglycerides & $1.11(0.98-1.23)$ & 0.12 \\
\hline
\end{tabular}

Acronyms: ICH: intracerebral hemorrhage; PRS (polygenic risk score); $\mathrm{Cl}$ : confidence interval; LDL: lowdensity lipoprotein; HDL: high-density lipoprotein. 
Table 5: Mendelian randomization analysis of genetically instrumented lipid levels and risk of ICH.

\begin{tabular}{|c|c|c|c|c|c|}
\hline Mendelian & & \multicolumn{2}{|c|}{ Total Cholesterol } & \multicolumn{2}{|c|}{ LDL Cholesterol } \\
\hline Method & & OR (95\%Cl) & $\mathbf{P}$ & OR (95\%Cl) & $\mathbf{P}$ \\
\hline Ratio method & $\begin{array}{c}\text { Polygenic risk score } \\
\text { using on individual level data }\end{array}$ & $0.77(0.6-0.98)$ & 0.03 & $0.59(0.42-0.82)$ & 0.002 \\
\hline IVW & $\begin{array}{c}\text { Multiple SNPs } \\
\text { using summary level data }\end{array}$ & $0.84(0.72-0.99)$ & 0.04 & $0.65(0.52-0.82)$ & $<0.001$ \\
\hline Weighted median & $\begin{array}{c}\text { Multiple SNPs } \\
\text { using summary level data }\end{array}$ & $0.95(0.72-1.30)$ & 0.74 & $0.79(0.56-1.10)$ & 0.20 \\
\hline $\begin{array}{c}\text { MR-Egger } \\
\text { (Causal estimates) }\end{array}$ & $\begin{array}{c}\text { Multiple SNPs } \\
\text { using summary level data }\end{array}$ & $0.87(0.66-1.20)$ & 0.33 & $0.72(0.48-1.10)$ & 0.10 \\
\hline $\begin{array}{l}\text { MR-Egger } \\
\text { (Intercept) }\end{array}$ & $\begin{array}{c}\text { Multiple SNPs } \\
\text { using summary level data }\end{array}$ & $1.00(0.99-1.01)$ & 0.81 & $1.00(0.98-1.01)$ & 0.59 \\
\hline
\end{tabular}

Acronyms: ICH: intracerebral hemorrhage; LDL: low-density lipoprotein; OR: odds ratio; Cl: confidence interval; SNPs: single nucleotide polymorphisms; IVW: inverse variance weighted. 
Table 6. Sensitivity MR analyses evaluating the effect of genetically-determined LDL cholesterol on risk of different types of ischemic stroke: comparison of results using effect estimates for lipids using GLGC and the UK Biobank.

\begin{tabular}{|l|c|c|c|}
\hline $\begin{array}{c}\text { Ischemic stroke } \\
\text { subtype }\end{array}$ & $\begin{array}{c}\text { Lipid estimates from the GLGC } \\
2019 \text { Valdes-Marquez et al* }\end{array}$ & $\begin{array}{c}\text { Lipid estimates from the GLGC } \\
\text { 2018 Hindy et al** }\end{array}$ & $\begin{array}{c}\text { Lipid estimates from the } \\
\text { UK Biobank (this study) }\end{array}$ \\
\hline Cardioembolic & $1.06(0.84-1.33)$ & $0.99(0.84-1.16)$ & $1.05(0.97-1.13)$ \\
\hline Large artery & $1.10(0.82-1.47)$ & $1.28(1.07-1.53)$ & $1.37(1.24-1.51)$ \\
\hline Small vessel & $1.14(0.88-1.48)$ & $1.09(0.93-1.28)$ & $1.12(1.03-1.22)$ \\
\hline
\end{tabular}

Acronyms: MR: Mendelian Randomization; LDL: low-density lipoprotein; GLGC: Global Lipids Genetics Consortium; UK: United Kingdom.

* Neurology. 2019 Mar 12;92(11):e1176-e1187. ** Stroke. 2018 Apr;49(4):820-827. 
Table 7: Location-specific results for ICH risk.

\begin{tabular}{|c|c|c|c|c|c|c|}
\hline \multirow{2}{*}{ Lipid trait } & \multicolumn{3}{|l|}{$\begin{array}{l}\text { Lobar ICH } \\
n=539 \text { cases }\end{array}$} & \multicolumn{3}{|l|}{$\begin{array}{l}\text { Nonlobar ICH } \\
n=704 \text { cases }\end{array}$} \\
\hline & OR $(95 \% \mathrm{Cl})$ & $\mathbf{P}$ & $\begin{array}{c}\text { Metanalysis } \\
\text { Heterogeneity P }\end{array}$ & OR $(95 \% \mathrm{Cl})$ & $\mathbf{P}$ & $\begin{array}{c}\text { Metanalysis } \\
\text { Heterogeneity P }\end{array}$ \\
\hline \multicolumn{7}{|c|}{ Polygenic risk score analysis * } \\
\hline Total cholesterol & $0.89(0.80-0.99)$ & 0.03 & 0.42 & $0.94(0.85-1.08)$ & 0.20 & 0.96 \\
\hline LDL cholesterol & $0.81(0.73-0.89)$ & $<0.001$ & 0.96 & $0.90(0.82-0.99)$ & 0.04 & 0.99 \\
\hline \multicolumn{7}{|c|}{ Mendelian randomization analysis ** } \\
\hline Total cholesterol & $0.70(0.51-0.96)$ & 0.03 & - & $0.73(0.62-1.11)$ & 0.20 & - \\
\hline LDL cholesterol & $0.41(0.27-0.64)$ & $<0.001$ & - & $0.66(0.44-0.97)$ & 0.04 & - \\
\hline
\end{tabular}

Acronyms: ICH: Intracerebral hemorrhage; PRS: polygenic risk score; OR: odds ratio; Cl: confidence intervals; LDL: low-density lipoprotein.

* Inverse variance fixed effects metanalysis of logistic regression results for ICH across GOCHA, ISGC ICH GWAS and GERFHS. For each study, the logistic regression model used $\mathrm{ICH}$ risk as the dependent variable and a polygenic risk score as the independent variable, adjusting for age, sex and 4 principal components. The PRS were normalized and entered to the model as a continuous predictor. The OR represents the change in the odds of $\mathrm{ICH}$ per each additional standard deviation of the PRS.

** Mendelian randomization results of genetically instrumented cholesterol levels using a polygenic risk score as the instrument. Each lipid fraction-specific analysis utilized the ratio method, taking the effect estimates for ICH PRS (numerator) and lipid level $\sim$ PRS (denominator). 


\section{Please wait...}

If this message is not eventually replaced by the proper contents of the document, your PDF viewer may not be able to display this type of document.

You can upgrade to the latest version of Adobe Reader for Windows®, Mac, or Linux® by visiting http://www.adobe.com/go/reader_download.

For more assistance with Adobe Reader visit http://www.adobe.com/go/acrreader.

Windows is either a registered trademark or a trademark of Microsoft Corporation in the United States and/or other countries. Mac is a trademark
of Apple Inc., registered in the United States and other countries. Linux is the registered trademark of Linus Torvalds in the U.S. and other countries. 
The full content of this file cannot be displayed with your current PDF viewer. Please update to the latest possible version to view this document. 


\section{Please wait...}

If this message is not eventually replaced by the proper contents of the document, your PDF viewer may not be able to display this type of document.

You can upgrade to the latest version of Adobe Reader for Windows®, Mac, or Linux® by visiting http://www.adobe.com/go/reader_download.

For more assistance with Adobe Reader visit http://www.adobe.com/go/acrreader.

Windows is either a registered trademark or a trademark of Microsoft Corporation in the United States and/or other countries. Mac is a trademark
of Apple Inc., registered in the United States and other countries. Linux is the registered trademark of Linus Torvalds in the U.S. and other countries. 


\section{Please wait...}

If this message is not eventually replaced by the proper contents of the document, your PDF viewer may not be able to display this type of document.

You can upgrade to the latest version of Adobe Reader for Windows®, Mac, or Linux® by visiting http://www.adobe.com/go/reader_download.

For more assistance with Adobe Reader visit http://www.adobe.com/go/acrreader.

Windows is either a registered trademark or a trademark of Microsoft Corporation in the United States and/or other countries. Mac is a trademark
of Apple Inc., registered in the United States and other countries. Linux is the registered trademark of Linus Torvalds in the U.S. and other countries. 


\section{Please wait...}

If this message is not eventually replaced by the proper contents of the document, your PDF viewer may not be able to display this type of document.

You can upgrade to the latest version of Adobe Reader for Windows®, Mac, or Linux® by visiting http://www.adobe.com/go/reader_download.

For more assistance with Adobe Reader visit http://www.adobe.com/go/acrreader.

Windows is either a registered trademark or a trademark of Microsoft Corporation in the United States and/or other countries. Mac is a trademark
of Apple Inc., registered in the United States and other countries. Linux is the registered trademark of Linus Torvalds in the U.S. and other countries. 


\section{Please wait...}

If this message is not eventually replaced by the proper contents of the document, your PDF viewer may not be able to display this type of document.

You can upgrade to the latest version of Adobe Reader for Windows®, Mac, or Linux® by visiting http://www.adobe.com/go/reader_download.

For more assistance with Adobe Reader visit http://www.adobe.com/go/acrreader.

Windows is either a registered trademark or a trademark of Microsoft Corporation in the United States and/or other countries. Mac is a trademark
of Apple Inc., registered in the United States and other countries. Linux is the registered trademark of Linus Torvalds in the U.S. and other countries. 
The full content of this file cannot be displayed with your current PDF viewer. Please update to the latest possible version to view this document. 


\section{Please wait...}

If this message is not eventually replaced by the proper contents of the document, your PDF viewer may not be able to display this type of document.

You can upgrade to the latest version of Adobe Reader for Windows®, Mac, or Linux® by visiting http://www.adobe.com/go/reader_download.

For more assistance with Adobe Reader visit http://www.adobe.com/go/acrreader.

Windows is either a registered trademark or a trademark of Microsoft Corporation in the United States and/or other countries. Mac is a trademark
of Apple Inc., registered in the United States and other countries. Linux is the registered trademark of Linus Torvalds in the U.S. and other countries. 


\section{Please wait...}

If this message is not eventually replaced by the proper contents of the document, your PDF viewer may not be able to display this type of document.

You can upgrade to the latest version of Adobe Reader for Windows®, Mac, or Linux® by visiting http://www.adobe.com/go/reader_download.

For more assistance with Adobe Reader visit http://www.adobe.com/go/acrreader.

Windows is either a registered trademark or a trademark of Microsoft Corporation in the United States and/or other countries. Mac is a trademark
of Apple Inc., registered in the United States and other countries. Linux is the registered trademark of Linus Torvalds in the U.S. and other countries. 


\section{Please wait...}

If this message is not eventually replaced by the proper contents of the document, your PDF viewer may not be able to display this type of document.

You can upgrade to the latest version of Adobe Reader for Windows®, Mac, or Linux® by visiting http://www.adobe.com/go/reader_download.

For more assistance with Adobe Reader visit http://www.adobe.com/go/acrreader.

Windows is either a registered trademark or a trademark of Microsoft Corporation in the United States and/or other countries. Mac is a trademark
of Apple Inc., registered in the United States and other countries. Linux is the registered trademark of Linus Torvalds in the U.S. and other countries. 


\section{Please wait...}

If this message is not eventually replaced by the proper contents of the document, your PDF viewer may not be able to display this type of document.

You can upgrade to the latest version of Adobe Reader for Windows®, Mac, or Linux® by visiting http://www.adobe.com/go/reader_download.

For more assistance with Adobe Reader visit http://www.adobe.com/go/acrreader.

Windows is either a registered trademark or a trademark of Microsoft Corporation in the United States and/or other countries. Mac is a trademark
of Apple Inc., registered in the United States and other countries. Linux is the registered trademark of Linus Torvalds in the U.S. and other countries. 


\section{Please wait...}

If this message is not eventually replaced by the proper contents of the document, your PDF viewer may not be able to display this type of document.

You can upgrade to the latest version of Adobe Reader for Windows®, Mac, or Linux® by visiting http://www.adobe.com/go/reader_download.

For more assistance with Adobe Reader visit http://www.adobe.com/go/acrreader.

Windows is either a registered trademark or a trademark of Microsoft Corporation in the United States and/or other countries. Mac is a trademark
of Apple Inc., registered in the United States and other countries. Linux is the registered trademark of Linus Torvalds in the U.S. and other countries. 


\section{Please wait...}

If this message is not eventually replaced by the proper contents of the document, your PDF viewer may not be able to display this type of document.

You can upgrade to the latest version of Adobe Reader for Windows®, Mac, or Linux® by visiting http://www.adobe.com/go/reader_download.

For more assistance with Adobe Reader visit http://www.adobe.com/go/acrreader.

Windows is either a registered trademark or a trademark of Microsoft Corporation in the United States and/or other countries. Mac is a trademark
of Apple Inc., registered in the United States and other countries. Linux is the registered trademark of Linus Torvalds in the U.S. and other countries. 


\section{Please wait...}

If this message is not eventually replaced by the proper contents of the document, your PDF viewer may not be able to display this type of document.

You can upgrade to the latest version of Adobe Reader for Windows®, Mac, or Linux® by visiting http://www.adobe.com/go/reader_download.

For more assistance with Adobe Reader visit http://www.adobe.com/go/acrreader.

Windows is either a registered trademark or a trademark of Microsoft Corporation in the United States and/or other countries. Mac is a trademark
of Apple Inc., registered in the United States and other countries. Linux is the registered trademark of Linus Torvalds in the U.S. and other countries. 


\section{Please wait...}

If this message is not eventually replaced by the proper contents of the document, your PDF viewer may not be able to display this type of document.

You can upgrade to the latest version of Adobe Reader for Windows®, Mac, or Linux® by visiting http://www.adobe.com/go/reader_download.

For more assistance with Adobe Reader visit http://www.adobe.com/go/acrreader.

Windows is either a registered trademark or a trademark of Microsoft Corporation in the United States and/or other countries. Mac is a trademark
of Apple Inc., registered in the United States and other countries. Linux is the registered trademark of Linus Torvalds in the U.S. and other countries. 


\section{Please wait...}

If this message is not eventually replaced by the proper contents of the document, your PDF viewer may not be able to display this type of document.

You can upgrade to the latest version of Adobe Reader for Windows®, Mac, or Linux® by visiting http://www.adobe.com/go/reader_download.

For more assistance with Adobe Reader visit http://www.adobe.com/go/acrreader.

Windows is either a registered trademark or a trademark of Microsoft Corporation in the United States and/or other countries. Mac is a trademark
of Apple Inc., registered in the United States and other countries. Linux is the registered trademark of Linus Torvalds in the U.S. and other countries. 
To view the full contents of this document, you need a later version of the PDF viewer. You can upgrade to the latest version of Adobe Reader from www.adobe.com/products/acrobat/readstep2.html

For further support, go to www.adobe.com/support/products/acrreader.html 


\section{Please wait...}

If this message is not eventually replaced by the proper contents of the document, your PDF viewer may not be able to display this type of document.

You can upgrade to the latest version of Adobe Reader for Windows®, Mac, or Linux® by visiting http://www.adobe.com/go/reader_download.

For more assistance with Adobe Reader visit http://www.adobe.com/go/acrreader.

Windows is either a registered trademark or a trademark of Microsoft Corporation in the United States and/or other countries. Mac is a trademark
of Apple Inc., registered in the United States and other countries. Linux is the registered trademark of Linus Torvalds in the U.S. and other countries. 


\section{Please wait...}

If this message is not eventually replaced by the proper contents of the document, your PDF viewer may not be able to display this type of document.

You can upgrade to the latest version of Adobe Reader for Windows®, Mac, or Linux® by visiting http://www.adobe.com/go/reader_download.

For more assistance with Adobe Reader visit http://www.adobe.com/go/acrreader.

Windows is either a registered trademark or a trademark of Microsoft Corporation in the United States and/or other countries. Mac is a trademark
of Apple Inc., registered in the United States and other countries. Linux is the registered trademark of Linus Torvalds in the U.S. and other countries. 


\section{Please wait...}

If this message is not eventually replaced by the proper contents of the document, your PDF viewer may not be able to display this type of document.

You can upgrade to the latest version of Adobe Reader for Windows®, Mac, or Linux® by visiting http://www.adobe.com/go/reader_download.

For more assistance with Adobe Reader visit http://www.adobe.com/go/acrreader.

Windows is either a registered trademark or a trademark of Microsoft Corporation in the United States and/or other countries. Mac is a trademark
of Apple Inc., registered in the United States and other countries. Linux is the registered trademark of Linus Torvalds in the U.S. and other countries. 


\section{Please wait...}

If this message is not eventually replaced by the proper contents of the document, your PDF viewer may not be able to display this type of document.

You can upgrade to the latest version of Adobe Reader for Windows®, Mac, or Linux® by visiting http://www.adobe.com/go/reader_download.

For more assistance with Adobe Reader visit http://www.adobe.com/go/acrreader.

Windows is either a registered trademark or a trademark of Microsoft Corporation in the United States and/or other countries. Mac is a trademark
of Apple Inc., registered in the United States and other countries. Linux is the registered trademark of Linus Torvalds in the U.S. and other countries. 


\section{Please wait...}

If this message is not eventually replaced by the proper contents of the document, your PDF viewer may not be able to display this type of document.

You can upgrade to the latest version of Adobe Reader for Windows®, Mac, or Linux® by visiting http://www.adobe.com/go/reader_download.

For more assistance with Adobe Reader visit http://www.adobe.com/go/acrreader.

Windows is either a registered trademark or a trademark of Microsoft Corporation in the United States and/or other countries. Mac is a trademark
of Apple Inc., registered in the United States and other countries. Linux is the registered trademark of Linus Torvalds in the U.S. and other countries. 


\section{Please wait...}

If this message is not eventually replaced by the proper contents of the document, your PDF viewer may not be able to display this type of document.

You can upgrade to the latest version of Adobe Reader for Windows®, Mac, or Linux® by visiting http://www.adobe.com/go/reader_download.

For more assistance with Adobe Reader visit http://www.adobe.com/go/acrreader.

Windows is either a registered trademark or a trademark of Microsoft Corporation in the United States and/or other countries. Mac is a trademark
of Apple Inc., registered in the United States and other countries. Linux is the registered trademark of Linus Torvalds in the U.S. and other countries. 


\section{Please wait...}

If this message is not eventually replaced by the proper contents of the document, your PDF viewer may not be able to display this type of document.

You can upgrade to the latest version of Adobe Reader for Windows®, Mac, or Linux® by visiting http://www.adobe.com/go/reader_download.

For more assistance with Adobe Reader visit http://www.adobe.com/go/acrreader.

Windows is either a registered trademark or a trademark of Microsoft Corporation in the United States and/or other countries. Mac is a trademark
of Apple Inc., registered in the United States and other countries. Linux is the registered trademark of Linus Torvalds in the U.S. and other countries. 


\section{Please wait...}

If this message is not eventually replaced by the proper contents of the document, your PDF viewer may not be able to display this type of document.

You can upgrade to the latest version of Adobe Reader for Windows®, Mac, or Linux® by visiting http://www.adobe.com/go/reader_download.

For more assistance with Adobe Reader visit http://www.adobe.com/go/acrreader.

Windows is either a registered trademark or a trademark of Microsoft Corporation in the United States and/or other countries. Mac is a trademark
of Apple Inc., registered in the United States and other countries. Linux is the registered trademark of Linus Torvalds in the U.S. and other countries. 


\section{Please wait...}

If this message is not eventually replaced by the proper contents of the document, your PDF viewer may not be able to display this type of document.

You can upgrade to the latest version of Adobe Reader for Windows®, Mac, or Linux® by visiting http://www.adobe.com/go/reader_download.

For more assistance with Adobe Reader visit http://www.adobe.com/go/acrreader.

Windows is either a registered trademark or a trademark of Microsoft Corporation in the United States and/or other countries. Mac is a trademark
of Apple Inc., registered in the United States and other countries. Linux is the registered trademark of Linus Torvalds in the U.S. and other countries. 


\section{Please wait...}

If this message is not eventually replaced by the proper contents of the document, your PDF viewer may not be able to display this type of document.

You can upgrade to the latest version of Adobe Reader for Windows®, Mac, or Linux® by visiting http://www.adobe.com/go/reader_download.

For more assistance with Adobe Reader visit http://www.adobe.com/go/acrreader.

Windows is either a registered trademark or a trademark of Microsoft Corporation in the United States and/or other countries. Mac is a trademark
of Apple Inc., registered in the United States and other countries. Linux is the registered trademark of Linus Torvalds in the U.S. and other countries. 


\section{Please wait...}

If this message is not eventually replaced by the proper contents of the document, your PDF viewer may not be able to display this type of document.

You can upgrade to the latest version of Adobe Reader for Windows®, Mac, or Linux® by visiting http://www.adobe.com/go/reader_download.

For more assistance with Adobe Reader visit http://www.adobe.com/go/acrreader.

Windows is either a registered trademark or a trademark of Microsoft Corporation in the United States and/or other countries. Mac is a trademark
of Apple Inc., registered in the United States and other countries. Linux is the registered trademark of Linus Torvalds in the U.S. and other countries. 


\section{Please wait...}

If this message is not eventually replaced by the proper contents of the document, your PDF viewer may not be able to display this type of document.

You can upgrade to the latest version of Adobe Reader for Windows®, Mac, or Linux® by visiting http://www.adobe.com/go/reader_download.

For more assistance with Adobe Reader visit http://www.adobe.com/go/acrreader.

Windows is either a registered trademark or a trademark of Microsoft Corporation in the United States and/or other countries. Mac is a trademark
of Apple Inc., registered in the United States and other countries. Linux is the registered trademark of Linus Torvalds in the U.S. and other countries. 


\section{Please wait...}

If this message is not eventually replaced by the proper contents of the document, your PDF viewer may not be able to display this type of document.

You can upgrade to the latest version of Adobe Reader for Windows®, Mac, or Linux® by visiting http://www.adobe.com/go/reader_download.

For more assistance with Adobe Reader visit http://www.adobe.com/go/acrreader.

Windows is either a registered trademark or a trademark of Microsoft Corporation in the United States and/or other countries. Mac is a trademark
of Apple Inc., registered in the United States and other countries. Linux is the registered trademark of Linus Torvalds in the U.S. and other countries. 


\section{Please wait...}

If this message is not eventually replaced by the proper contents of the document, your PDF viewer may not be able to display this type of document.

You can upgrade to the latest version of Adobe Reader for Windows®, Mac, or Linux® by visiting http://www.adobe.com/go/reader_download.

For more assistance with Adobe Reader visit http://www.adobe.com/go/acrreader.

Windows is either a registered trademark or a trademark of Microsoft Corporation in the United States and/or other countries. Mac is a trademark
of Apple Inc., registered in the United States and other countries. Linux is the registered trademark of Linus Torvalds in the U.S. and other countries. 


\section{Please wait...}

If this message is not eventually replaced by the proper contents of the document, your PDF viewer may not be able to display this type of document.

You can upgrade to the latest version of Adobe Reader for Windows®, Mac, or Linux® by visiting http://www.adobe.com/go/reader_download.

For more assistance with Adobe Reader visit http://www.adobe.com/go/acrreader.

Windows is either a registered trademark or a trademark of Microsoft Corporation in the United States and/or other countries. Mac is a trademark
of Apple Inc., registered in the United States and other countries. Linux is the registered trademark of Linus Torvalds in the U.S. and other countries. 
Table 1. Studies included in this analysis.

\begin{tabular}{|c|c|c|c|c|}
\hline Characteristic & UK Biobank & GOCHA & ISGC ICH Study & GERFHS \\
\hline Analytical stage & $\begin{array}{c}\text { Association } \\
\text { Cholesterol level } \sim \text { PRS }\end{array}$ & $\begin{array}{c}\text { Association } \\
\text { ICH Risk PRS }\end{array}$ & $\begin{array}{c}\text { Association } \\
\text { ICH Risk PRS }\end{array}$ & $\begin{array}{c}\text { Association } \\
\mathrm{ICH} \text { Risk PRS }\end{array}$ \\
\hline Study design & Cohort & Case / Control & Case / Control & Case / Control \\
\hline Study participants & 316,428 & $277 / 248$ & $563 / 523$ & $446 / 490$ \\
\hline Age, mean (SD) & $68(8)$ & $73(10) / 72(8)$ & 71 (14) / 66 (16) & 70 (14) / 68 (13) \\
\hline Female sex $n, \%$ & $170,871(54)$ & $130(47) / 123(50)$ & $252(45) / 255(49)$ & $211(47) / 235(48)$ \\
\hline Genotyping platform & $\begin{array}{c}\text { Affymetrix } \\
\text { UK Biobank array }\end{array}$ & $\begin{array}{c}\text { Illumina } \\
\text { HumanHap550 }\end{array}$ & $\begin{array}{c}\text { Illumina } \\
\text { HumanHap550 }\end{array}$ & Affymetrix 6.0 \\
\hline Genotyped SNPs & 820,967 & 527,508 & 527,508 & 580,491 \\
\hline Imputed SNPs & $73,355,667$ & $7,965,700$ & $7,965,700$ & $7,967,430$ \\
\hline
\end{tabular}

Acronyms: UK: United Kingdom; GOCHA: Genetics of Cerebral Hemorrhage with Anticoagulation; ISGC: International Stroke Genetics Consortium; GERFHS: Genetic and Environmental Risk Factors for Hemorrhagic Stroke; ICH: intracerebral hemorrhage; PRS: polygenic risk score; SNPs (single nucleotide polymorphisms); SD: standard deviation. 
Table 2. Association results for 4 PRS with their corresponding trait in the UK Biobank.

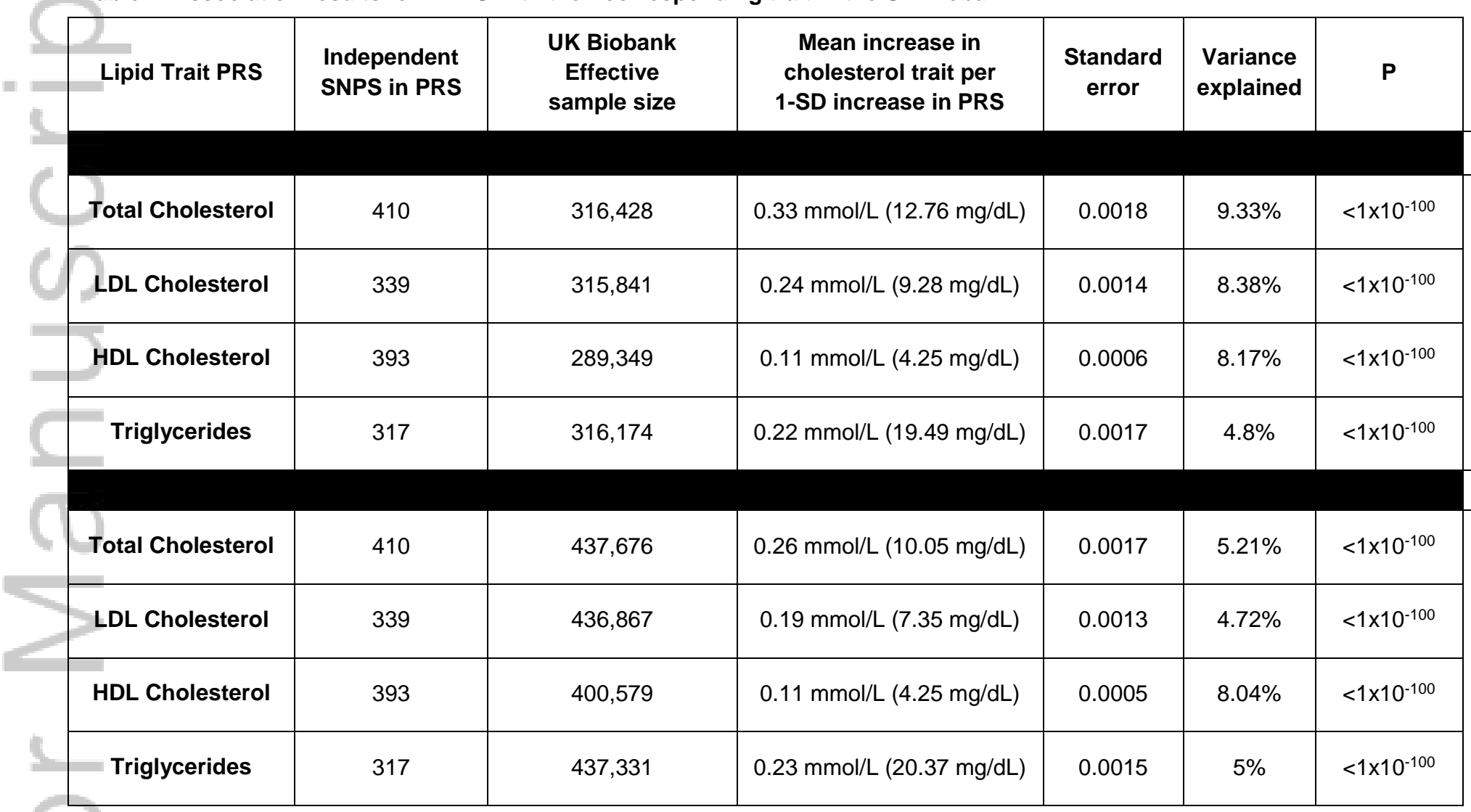

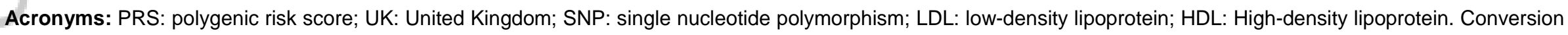
of $\mathrm{mmol} / \mathrm{L}$ to $\mathrm{mg} / \mathrm{dL}$ : for TC, $\mathrm{LDL}$ and $\mathrm{HDL} 1 \mathrm{mmol} / \mathrm{L}=38.67 \mathrm{mg} / \mathrm{dL}$; for triglycerides, $1 \mathrm{mmol} / \mathrm{L}=88.57 \mathrm{mg} / \mathrm{dL}$.

The primary analysis was restricted to unrelated study participant of genetically-determined European ancestry who were not taking lipid-lowering medications.

** The secondary analysis included all study participants of self-reported European ancestry without any other filters.

This article is protected by copyright. All rights reserved. 
Table 3: Study-specific and metanalysis of logistic regression results modeling ICH risk as a function of different PRS.

\begin{tabular}{|c|c|c|c|c|c|c|c|c|}
\hline \multirow{2}{*}{ Study } & \multicolumn{2}{|c|}{ Total Cholesterol } & \multicolumn{2}{|c|}{ LDL Cholesterol } & \multicolumn{2}{|c|}{ HDL Cholesterol } & \multicolumn{2}{|c|}{ Triglycerides } \\
\hline & OR (95\% Cl) & $\mathbf{P}$ & OR (95\% Cl) & $\mathbf{P}$ & OR (95\% Cl) & $\mathbf{P}$ & OR (95\% Cl) & $\mathbf{P}$ \\
\hline GOCHA & $0.95(0.80-1.14)$ & 0.59 & $0.93(0.78-1.11)$ & 0.41 & $1.12(0.94-1.34)$ & 0.20 & $0.95(0.80-1.14)$ & 0.59 \\
\hline ISGC ICH & $0.93(0.82-1.05)$ & 0.24 & $0.88(0.77-0.99)$ & 0.04 & $1.15(1.01-1.30)$ & 0.03 & $1.01(0.89-1.14)$ & 0.84 \\
\hline GERFHS & $0.88(0.77-1.01)$ & 0.07 & $0.85(0.75-0.97)$ & 0.02 & $0.99(0.86-1.12)$ & 0.84 & $1.19(1.04-1.36)$ & $\begin{array}{c}0.00 \\
9\end{array}$ \\
\hline $\begin{array}{l}\text { Fixed effects } \\
\text { Meta-analysis }\end{array}$ & $0.92(0.85-0.99)$ & 0.03 & $0.88(0.81-0.95)$ & 0.002 & $1.10(1.00-1.21)$ & 0.06 & $1.11(0.98-1.23)$ & 0.14 \\
\hline $\begin{array}{l}\text { Random Effects } \\
\text { Meta-analysis }\end{array}$ & $0.92(0.84-0.99)$ & 0.03 & $0.88(0.81-0.95)$ & 0.002 & $1.08(0.98-1.19)$ & 0.13 & $1.05(0.93-1.20)$ & 0.42 \\
\hline Heterogeneity & $1^{2}=0 \%$ & 0.77 & $1^{2}=0 \%$ & 0.75 & $I^{2}=32 \%$ & 0.23 & $\mathrm{I}^{2}=60 \%$ & 0.08 \\
\hline
\end{tabular}

Acronyms: ICH: intracerebral hemorrhage; PRS (polygenic risk score); LDL: low-density lipoprotein; HDL: high-density lipoprotein; Cl: confidence interval; GOCHA: Genetics of Cerebral Hemorrhage with Anticoagulation; ISGC: International Stroke Genetics Consortium; GERFHS: Genetic and Environmental Risk Factors for Hemorrhagic Stroke; FE: Fixed-Effects. RE: Random effects. Het-p: heterogeneity$p$ for the metanalysis. 
Table 4: Metanalysis of logistic regression results modeling ICH risk as a function of different PRS, excluding CETP variants.

\begin{tabular}{|c|c|c|}
\hline Lipid PRS & OR (95\% Cl) & P \\
\hline Total Cholesterol & $0.91(0.84-0.99)$ & 0.03 \\
\hline LDL Cholesterol & $0.88(0.81-0.96)$ & 0.003 \\
\hline HDL Cholesterol & $1.12(0.99-1.21)$ & 0.08 \\
\hline Triglycerides & $1.11(0.98-1.23)$ & 0.12 \\
\hline
\end{tabular}

Acronyms: ICH: intracerebral hemorrhage; PRS (polygenic risk score); $\mathrm{Cl}$ : confidence interval; LDL: lowdensity lipoprotein; HDL: high-density lipoprotein. 
Table 5: Mendelian randomization analysis of genetically instrumented lipid levels and risk of ICH.

\begin{tabular}{|c|c|c|c|c|c|}
\hline Mendelian & & \multicolumn{2}{|c|}{ Total Cholesterol } & \multicolumn{2}{|c|}{ LDL Cholesterol } \\
\hline Method & & OR (95\%Cl) & $\mathbf{P}$ & OR (95\%Cl) & $\mathbf{P}$ \\
\hline Ratio method & $\begin{array}{c}\text { Polygenic risk score } \\
\text { using on individual level data }\end{array}$ & $0.77(0.6-0.98)$ & 0.03 & $0.59(0.42-0.82)$ & 0.002 \\
\hline IVW & $\begin{array}{c}\text { Multiple SNPs } \\
\text { using summary level data }\end{array}$ & $0.84(0.72-0.99)$ & 0.04 & $0.65(0.52-0.82)$ & $<0.001$ \\
\hline Weighted median & $\begin{array}{c}\text { Multiple SNPs } \\
\text { using summary level data }\end{array}$ & $0.95(0.72-1.30)$ & 0.74 & $0.79(0.56-1.10)$ & 0.20 \\
\hline $\begin{array}{c}\text { MR-Egger } \\
\text { (Causal estimates) }\end{array}$ & $\begin{array}{c}\text { Multiple SNPs } \\
\text { using summary level data }\end{array}$ & $0.87(0.66-1.20)$ & 0.33 & $0.72(0.48-1.10)$ & 0.10 \\
\hline $\begin{array}{l}\text { MR-Egger } \\
\text { (Intercept) }\end{array}$ & $\begin{array}{c}\text { Multiple SNPs } \\
\text { using summary level data }\end{array}$ & $1.00(0.99-1.01)$ & 0.81 & $1.00(0.98-1.01)$ & 0.59 \\
\hline
\end{tabular}

Acronyms: ICH: intracerebral hemorrhage; LDL: low-density lipoprotein; OR: odds ratio; Cl: confidence interval; SNPs: single nucleotide polymorphisms; IVW: inverse variance weighted. 
Table 6. Sensitivity MR analyses evaluating the effect of genetically-determined LDL cholesterol on risk of different types of ischemic stroke: comparison of results using effect estimates for lipids using GLGC and the UK Biobank.

\begin{tabular}{|l|c|c|c|}
\hline $\begin{array}{c}\text { Ischemic stroke } \\
\text { subtype }\end{array}$ & $\begin{array}{c}\text { Lipid estimates from the GLGC } \\
2019 \text { Valdes-Marquez et al* }\end{array}$ & $\begin{array}{c}\text { Lipid estimates from the GLGC } \\
\text { 2018 Hindy et al** }\end{array}$ & $\begin{array}{c}\text { Lipid estimates from the } \\
\text { UK Biobank (this study) }\end{array}$ \\
\hline Cardioembolic & $1.06(0.84-1.33)$ & $0.99(0.84-1.16)$ & $1.05(0.97-1.13)$ \\
\hline Large artery & $1.10(0.82-1.47)$ & $1.28(1.07-1.53)$ & $1.37(1.24-1.51)$ \\
\hline Small vessel & $1.14(0.88-1.48)$ & $1.09(0.93-1.28)$ & $1.12(1.03-1.22)$ \\
\hline
\end{tabular}

Acronyms: MR: Mendelian Randomization; LDL: low-density lipoprotein; GLGC: Global Lipids Genetics Consortium; UK: United Kingdom.

* Neurology. 2019 Mar 12;92(11):e1176-e1187. ** Stroke. 2018 Apr;49(4):820-827. 
Table 7: Location-specific results for ICH risk.

\begin{tabular}{|c|c|c|c|c|c|c|}
\hline \multirow{2}{*}{ Lipid trait } & \multicolumn{3}{|l|}{$\begin{array}{l}\text { Lobar ICH } \\
n=539 \text { cases }\end{array}$} & \multicolumn{3}{|l|}{$\begin{array}{l}\text { Nonlobar ICH } \\
n=704 \text { cases }\end{array}$} \\
\hline & OR $(95 \% \mathrm{Cl})$ & $\mathbf{P}$ & $\begin{array}{c}\text { Metanalysis } \\
\text { Heterogeneity P }\end{array}$ & OR $(95 \% \mathrm{Cl})$ & $\mathbf{P}$ & $\begin{array}{c}\text { Metanalysis } \\
\text { Heterogeneity P }\end{array}$ \\
\hline \multicolumn{7}{|c|}{ Polygenic risk score analysis * } \\
\hline Total cholesterol & $0.89(0.80-0.99)$ & 0.03 & 0.42 & $0.94(0.85-1.08)$ & 0.20 & 0.96 \\
\hline LDL cholesterol & $0.81(0.73-0.89)$ & $<0.001$ & 0.96 & $0.90(0.82-0.99)$ & 0.04 & 0.99 \\
\hline \multicolumn{7}{|c|}{ Mendelian randomization analysis ** } \\
\hline Total cholesterol & $0.70(0.51-0.96)$ & 0.03 & - & $0.73(0.62-1.11)$ & 0.20 & - \\
\hline LDL cholesterol & $0.41(0.27-0.64)$ & $<0.001$ & - & $0.66(0.44-0.97)$ & 0.04 & - \\
\hline
\end{tabular}

Acronyms: ICH: Intracerebral hemorrhage; PRS: polygenic risk score; OR: odds ratio; Cl: confidence intervals; LDL: low-density lipoprotein.

* Inverse variance fixed effects metanalysis of logistic regression results for ICH across GOCHA, ISGC ICH GWAS and GERFHS. For each study, the logistic regression model used $\mathrm{ICH}$ risk as the dependent variable and a polygenic risk score as the independent variable, adjusting for age, sex and 4 principal components. The PRS were normalized and entered to the model as a continuous predictor. The OR represents the change in the odds of $\mathrm{ICH}$ per each additional standard deviation of the PRS.

** Mendelian randomization results of genetically instrumented cholesterol levels using a polygenic risk score as the instrument. Each lipid fraction-specific analysis utilized the ratio method, taking the effect estimates for ICH PRS (numerator) and lipid level $\sim$ PRS (denominator). 


\section{Please wait...}

If this message is not eventually replaced by the proper contents of the document, your PDF viewer may not be able to display this type of document.

You can upgrade to the latest version of Adobe Reader for Windows®, Mac, or Linux® by visiting http://www.adobe.com/go/reader_download.

For more assistance with Adobe Reader visit http://www.adobe.com/go/acrreader.

Windows is either a registered trademark or a trademark of Microsoft Corporation in the United States and/or other countries. Mac is a trademark
of Apple Inc., registered in the United States and other countries. Linux is the registered trademark of Linus Torvalds in the U.S. and other countries. 


\section{Please wait...}

If this message is not eventually replaced by the proper contents of the document, your PDF viewer may not be able to display this type of document.

You can upgrade to the latest version of Adobe Reader for Windows®, Mac, or Linux® by visiting http://www.adobe.com/go/reader_download.

For more assistance with Adobe Reader visit http://www.adobe.com/go/acrreader.

Windows is either a registered trademark or a trademark of Microsoft Corporation in the United States and/or other countries. Mac is a trademark
of Apple Inc., registered in the United States and other countries. Linux is the registered trademark of Linus Torvalds in the U.S. and other countries. 


\section{Please wait...}

If this message is not eventually replaced by the proper contents of the document, your PDF viewer may not be able to display this type of document.

You can upgrade to the latest version of Adobe Reader for Windows®, Mac, or Linux® by visiting http://www.adobe.com/go/reader_download.

For more assistance with Adobe Reader visit http://www.adobe.com/go/acrreader.

Windows is either a registered trademark or a trademark of Microsoft Corporation in the United States and/or other countries. Mac is a trademark
of Apple Inc., registered in the United States and other countries. Linux is the registered trademark of Linus Torvalds in the U.S. and other countries. 


\section{Please wait...}

If this message is not eventually replaced by the proper contents of the document, your PDF viewer may not be able to display this type of document.

You can upgrade to the latest version of Adobe Reader for Windows®, Mac, or Linux® by visiting http://www.adobe.com/go/reader_download.

For more assistance with Adobe Reader visit http://www.adobe.com/go/acrreader.

Windows is either a registered trademark or a trademark of Microsoft Corporation in the United States and/or other countries. Mac is a trademark
of Apple Inc., registered in the United States and other countries. Linux is the registered trademark of Linus Torvalds in the U.S. and other countries. 